\title{
SER NIÑO EN UN ENTORNO INDUSTRIAL CONTEMPORÁNEO. EJEMPLOS DESDE LA SIERRA MINERA DE CARTAGENA-LA UNIÓN (MURCIA)
}

\author{
Being a Child in an Industrial Contemporaneous Environment. Examples \\ from the Mining Mountains of Cartagena-La Unión (Murcia)
}

Óscar GONZÁlez VERGARA ${ }^{1}$ Universidad de Murcia / UNED o.gonzalezvergara@um.es

Fecha de recepción: $17-\mathrm{I}-2013$ Fecha de aceptación: 6-II-2013

Resumen: En este trabajo expondremos varios aspectos relativos a la infancia en un entorno industrial, centrándonos sobre todo al fenómeno del trabajo infantil. Para ello extraeremos ejemplos de uno de los complejos industriales mineros más importantes de la España contemporánea, la cuenca minera de la Cartagena-La Unión, donde el trabajo infantil estaba muy generalizado. Completaremos esta visión de la infancia con los ejemplos disponibles en los cantes mineros, donde se reflejan muchos aspectos de la niñez.

Palabras clave: infancia, minería, industria, época contemporánea, trabajo infantil.

AвSTRACт: This paper will discuss various aspects of childhood in an industrial environment, focusing particularly the phenomenon of child labor. We will draw examples from one of the most important industrial mining complex of contemporary Spain, the mining area in Cartagena-La Union, where child labor was widespread. We will complete this vision of childhood with the examples available in the mining songs, which reflect many aspects of childhood.

Keywords: childhood, mining, industry, contemporany times, child labor.

Licenciado en Historia, Master en Arqueología Aplicada (UMU). Actualmente estudiante de Grado de Filosofía (UNED) y Doctorando en Arqueología (UMU). 


\section{INTRODUCCIÓN}

En este trabajo mostraremos algunos de los aspectos fundamentales relacionados con la infancia en el entorno minero e industrial de la Sierra Minera de Cartagena-La Unión (Murcia) en época contemporánea. En concreto, las referencias existentes a su explotación laboral en los complejos industriales mineros, no solo de interior (minas, galerías) sino también en el exterior en actividades tan diversas como el transporte, lavado y concentrado del mineral.

Para ello, tras una introducción al espacio y el tiempo que nos ocupa (la Sierra Minera de Cartagena-La Unión en entre fines del siglo XIX y principios del XX), expondremos algunas razones antropológicas, económicas, sociopolíticas, religiosas, etc., que nos ayuden a entender la infancia, y en concreto la presencia de nińos en las minas.

\section{CONTEXTUALIZACIÓN HISTÓRICO-GEOGRÁFICA A LA SIERRA MINERA DE CARTAGENA-LA UNIÓN (MURCIA)}

El mero intento de contextualizar lo relativo al tiempo y el espacio en esta Sierra Minera implica contextualizar también la importancia que en ella ha tenido, en su dilatada historia, la explotación minera, verdadero vehículo, en época antigua y contemporánea, de la vida económica y social. Lo minero rezuma en la toponimia, la cultura material, la cultura inmaterial y el paisaje, y también la infancia tiene relación en estos espacios industriales con la minería, pero este último aspecto lo abordaremos más tarde. De momento, contextualizamos brevemente la historia y la geografía de este enclave murciano en época contemporánea.

El actual municipio de La Unión, creado en 1860, segregado de Cartagena, tiene una innegable vinculación minera ${ }^{2}$. Se creó en medio de la Sierra Minera por y para la minería, y por intereses económicos (mineros, claro está), y no tanto políticos. Dicha Sierra, dicho enclave minero, ha conocido la minería, como mínimo, desde la presencia romana en la zona. Son más dudosas las anteriores explotaciones púnicas e ibéricas, dudas procedentes sobretodo de la inexistencia de fuentes documentales fiables (escritas y arqueológicas). Con Roma implantada en la Sierra y teniendo a Cartagena (Carthago Nova) como núcleo organizador y explotador, la Sierra vio horadada sus entrañas para la explotación de plomo y plata (galena argentífera), tal y como muestran enclaves arqueológicos como el Cabezo Rajao. Tras la caída de Roma, la llegada de los germanos y la Alta Edad Media, la tradición historiográfica hace ver que tanto el poblamiento como la explotación minera cayeron en el olvido, remontándose, de forma intermitente y muy

2 Para una síntesis sobre el contexto histórico de esta ciudad, ver LÓPEZ MORELL y PERCEVAL VERDE, 2010 y SAURA VIVANCOS, 2004. En lo referente a una historia de la vida cotidiana en dicha localidad, ver: PÉREZ DE PERCEVAL, 2004. 
lentamente, desde fines del medievo y durante toda la modernidad, siendo a fines del siglo XIX cuando la explotación minera consiguiera, y quizás superara, las explotaciones extraídas por los romanos siglos atrás. Referencias islámicas, algunas enfatizando la presencia romana y andalusí en el sur de la península Ibérica hablan, del conocimiento de las ricas explotaciones de plomo y plata de la Sierra Minera, pero no hay evidencia documental y arqueológica de su explotación hasta fines del medievo ${ }^{3}$ y sobre todo a partir del siglo $\mathrm{XVI}^{4}$, donde hay constancia de cesiones mineras para la explotación de las riquezas de la Sierra, ya no tanto plomo y plata, sino sobre todo alumbre, mineral muy usado en la industria, por ejemplo, como mordiente en la industria textil.

En el siglo XIX, el Sudeste en general vive, auspiciado por la tardía Revolución Industrial y las necesidades, tanto internas como externas, de metales como el hierro o el plomo ${ }^{5}$. Almería fue uno de los primeros núcleos mineros en explotarse con este fin, y fueron precisamente almerienses los que fueron internándose en los núcleos mineros de Murcia como el de Cartagena-La Unión, cuando las explotaciones en Andalucía se fueron agotando. En un principio, se explotó en la Sierra Minera los pocos filones en superficie de plomo y plata (sobre todo en forma de carbonatos), y de una forma muy parecida a cómo fueron explotados por los romanos y en las concesiones medievales y modernas. Pronto, esta minería superficial y orientada en seguir las ricas vetas de mineral se acabó debido a que cada vez las materiales a explotar estaban a más profundidad, y con menor ley metálica, lo que exigía grandes inversiones como en entibado de las minas, su desagüe e incluir mejoras tecnológicas (sobre todo en hornos y lavaderos) para extraer el metal de forma rentable sobre todo en los más difíciles trabajos de sulfuros. Esta minería «mejorada» será la que reinará sobre todo en la segunda mitad del siglo XX, muy relacionado con el periodo de la autarquía franquista y las décadas posteriores, siendo el macrocomplejo del Lavadero

Por ejemplo, muchos investigadores recogen documentación que apoyaría esta idea de explotación minera de la Sierra a fines del medievo, con documentos como el de las Cortes de Briviesca de 1387.

4 Los ejemplos son más numerosos. Del reinado de Carlos I tenemos que en 1527 se cede a Francisco de Cobos la explotación de la Sierra Minera «[...] por la décima parte sobre los minerales de oro, plata, azogue, caparrosa, hierro, plomo y otros metales de la Sierra de Cartagena y su término y jurisdicción, con seis leguas alrededor»; en 1534 el mismo Francisco de Cobos tiene la concesión de los alumbres del Obispado de Cartagena, que para 1539 se hizo merced de la mitad al duque de Escalona, Diego López Pacheco; o Fernando del Castillo construye en El Garbanzal, por estas fechas, una torre vigía (Torre-Blanca) para proteger la zona ante las incursiones terrestres de los moriscos. Del reinado de Felipe II tenemos, por ejemplo, la concesión a Felipe del Río en 1587 para que beneficiara los minerales del Sancti Spiritu y el Acta Capitular de 6 de febrero de 1590 por una querella acerca de los problemas ocasionados por los hoyos que en el Llano de Pormán (Portmán) y El Gorguel fruto de la extracción de plomo. Esta situación continúa con Felipe III, que autoriza la explotación en Portmán, Felipe IV hace lo mismo con Vicente Imperialii, dando, finalmente, Carlos III, en 1696, licencia de las minas de plata de El Garbanzal a Mateo Roca y Ginés Jiménez.

5 Para contextualizar económicamente la explotación minera ver: VILAR, EGEA BRUNO y FERNÁNDEZ GUTIÉRREZ, 1990, y VILAR, EGEA BRUNO y VICTORIA, 1991. 
Roberto de Portmán su seña de identidad. Antes de la llegada de esta minería, cuando la minería de filones no era rentable, muchos mineros pasaron a explotar los escoriales mineros de los romanos que todavía contenían productos que podían ser extraídos si se volvían a fundir.

En este siglo XIX y las primeras décadas del XX, como sin duda en el pasado, y relacionado con una situación económica y laboral muy diferente a la actual, los niños eran usados y explotados en las labores mineras. En muchos casos la legislación lo permitió, pero conforme el Estado fue prohibiendo el uso de niños para el trabajo fueron la necesidad y la costumbre las que seguían manteniendo la explotación infantil en las diversas labores del proceso industrial minero. Sobre esto, continuaremos en el siguiente apartado.

\section{CONTEXTUALIZANDO LA INFANCIA EN EL TRABAJO MINERO. ENTRE LA NECESIDAD Y EL INFANTICIDIO}

Antes de comenzar a tratar el reflejo de la infancia y el nińo minero en la Sierra Minera de Cartagena-La Unión, me gustaría comentar someramente el siguiente texto:

[...] el espectáculo tristísimo que ofrecen cientos de criaturas trabajando en los lavaderos catorce horas diarias por tres o cuatro perras gordas, siendo más noble, más humano, más honrado, que las madres de esos niños se prostituyeran y vendieran sus cuerpos; que sus padres salgan al camino armados de trabucos para desvalijar a los viandantes, a explotar de la forma innoble en que lo hacen, las escasísimas energías físicas de criaturas que no han llegado a desarrollarse (Gabriel Lorca Navas, Heraldo de Mazarrón, 16-9-1913).

Dicho texto puede servir de ejemplo de algo que era muy cotidiano, y que anteriormente hemos ido comentando: la presencia del nińo en la mina, en este ejemplo concreto, en un lavadero de mineral. Era natural para 1913 dicho «espectáculo», pero también, y de ahí quizás lo curioso, el rechazo que muestra este Gabriel Lorca Navas. Considera que la indignación por esto es aún peor que otros delitos como el de la prostitución o el robo, calificándolos a estos últimos de más honrados y humanos que enviar a los niños a trabajar en las minas. Que sirva esta consideración para todo lo que se comentará en este apartado.

El empleo de los niños para el trabajo ha sido lo habitual prácticamente en toda la Historia de la Humanidad ${ }^{6}$. Maureira (2002: 114) afirma que «El trabajo infantil es un

6 Para una visión general acerca del trabajo de los niños en la Historia ver: MAUREIRA ESTRADA, 2002; SCHILDKROUT, 1980. Para el contexto contemporáneo y minero ver: PÉREZ DE PERCEVAL VERDE y SÁNCHEZ PICÓN, 2005. 
fenómeno de antigua data, pero que se recrea constantemente asumiendo características específicas según sea la relación que establece con otros fenómenos sociales, por esta razón sólo es posible identificarlos genéricamente en el tiempo, pero no caracterizarlo de manera única» ${ }^{7}$. Solamente en tiempos contemporáneos, fruto quizá de la Ilustración, la Democracia, una nueva moral y una nueva forma de entender lo humano y lo económico, se llegó a la conclusión de que el único trabajo de los nińos debía ser el de formarse, jugar y vivir su infancia; valores, como se observa, muy en relación con los estados del bienestar, de la democracia y la civilización (no paso aquí a valorar cuán manipulado y etnocéntrico resulta este concepto de "civilización" y muchas de las cosas relacionadas con él). Pero en entornos con grandes bolsas de pobreza, analfabetismo y necesidades varias, dichas ideas «bondadosas», «ilustradas» y "civilizadas» acerca de que el niño sólo debía preocuparse por aquello que era consustancial a su infancia, no existían. Un ejemplo pudiera ser el entorno minero de Cartagena-La Unión, donde los niños fueron usados como mano de obra (en muchos casos la principal). Algunos autores han escrito ya acerca de este "drama social», drama que aquí retomamos, matizamos y en parte ampliamos $^{8}$. Y no fueron los únicos espacios de trabajo donde la mano de obra infantil se permitía y fomentaba. Las razones, paso aquí a valorar el ejemplo minero murciano que nos ocupa, eran en parte económicas, y recalco lo de «en parte». Por ejemplo, a los nińos se les pagaba menos, su «sueldo» era un complemento para la economía familiar, y permitía al empresario no tener que invertir demasiado en labores de entibado de las minas, haciendo estas más estrechas y largas, con las dimensiones justas para que un nińo cupiera, extrajera el mineral y lo transportara al exterior. Los niños eran usados también en otras labores mineras pero de exterior como el lavado, poniendo, por ejemplo, en funcionamiento, el mecanismo de los rumbos.

Pero me atrevo a advertir si no hay otras razones, además de las económicas, para comprender mejor el porqué del mantenimiento de esta forma de trabajo que las leyes y la cultura oficial intentaron erradicar y que la necesidad económica (¿y antropológica?) fomentaba su continuación y no su cese. Me refiero, aunque quizás con necesarios matices, a una cierta pervivencia, en casos como este de extrema necesidad, de infanticidio, concretamente, aquel infanticidio denominado por M. Harris como por «negligencia», dejadez, infanticidio indirecto. Este autor llamó la atención sobre la necesidad de estudiar este fenómeno, el infanticidio, que ha estado presente en toda la Humanidad, no sólo en aquellas sociedades primitivas (de bandas, por ejemplo), en el que el infanticidio era usado como un método de control de la población, teniendo la ventaja, frente al

7 En el resto del artículo el autor ofrece una mirada antropológica, sociológica y económica del trabajo infantil, sobretodo de la época actual y en América Latina, pero parte de las reflexiones manifiestas nos son válidas al ser reflexiones universales.

8 GUILLÉN RIQUELME, 2009; MOUZO PAGÁN, 2003; VILAR, EGEA BRUNO, VICTORIA, 1987. 
aborto, de no entrañar riesgos físicos en las embarazadas ${ }^{9}$. A veces, la frontera que separa el infanticidio del aborto es muy sutil; una frontera que no se disuelve al entrar los «pueblos» en épocas ilustradas, democráticas y civilizadas.

Si analizamos someramente el contexto socioeconómico de un entorno como el de la Sierra Minera a finales del siglo XIX y parte del XX -escasez de alimentos, superpoblación en muchos casos por la gran cantidad de mano de obra en las minas, una moral católica que hacía imposible relaciones sexuales en matrimonio no conducentes a la reproducción, la prohibición del aborto, etc.-, el enviar a los niños a trabajar a la mina era, por una parte, una forma de obtener un dinero con qué alimentarlos -sin que ello redundara en una merma, a priori, de los recursos para alimentar a los adultos-, pero también la posibilidad de una muerte casi segura para el infante o un periodo de enseñanza de la profesión minera. El niño minero a menudo sufría, como cualquier otro minero o quizás más, de accidentes en la mina y entornos adyacentes -explosiones, derrumbamientos, etc. ${ }^{10}$, quedaba minusválido o enfermo -amputaciones, ceguera, silicosis, saturnismo, asma, reuma, artrosis, etc.-, y era muy posible que la muerte acabara sobreviniéndole antes de llegar a la edad adulta. Y en el caso de que llegara el nińo a la juventud y madurez, tenía la experiencia y fortaleza (que no aportaba ninguna academia) como para labrarse cierto futuro en el trabajo minero, aunque dicho futuro fuera simplemente ser poseedor de trabajo constante.

Quizás, es una hipótesis necesitada de teorización y más documentación, pero dentro de la mentalidad del momento, el enviar al nińo a la mina, a toparse frente a frente con las Parcas, quizás era una forma de hacer realidad un deseo interno e inexpresable de eliminar una boca que alimentar, volviendo a los medios de control de la población del pasado. Ello no dista demasiado a aquellos entornos de Brasil donde las madres se escudaban en creer que los niños en apariencia débil eran ángeles por lo que no había que alimentarlos, ya que su sitio era otro ${ }^{11}$; o las innumerables ocasiones en la que se documenta la presencia de expósitos en puertas de asilos y conventos (que en muchos

9 «Hasta hace poco, los antropólogos [aquí se puede añadir cualquier científico social o humanístico] no han empezado a admitir la posibilidad de que una parte considerable de los fallecimientos de recién nacidos y niños que antes se atribuían a los efectos inevitables del hambre y las enfermedades [o consecuencias de accidentes y enfermedades laborales de la industria y otros trabajos] representen en realidad formas sutiles de infanticidio fáctico» (HARRIS, 2010: 196).

10 Ejemplos en la prensa de estos accidentes de niños tenemos las siguientes noticias: «[...] que ayer mañana, un muchacho de los que se ocupan del tiro en la mina "Julio César», cayó al fondo y murió en el acto» (El Eco de Cartagena de 26-10-1874); «[...] hace días se desprendió un canto del techo de un minado, ocasionando la muerte a dos muchachos dedicados al transporte interior. La desgracia ha sido casual y las labores estaban en buen estado» (El Eco de Cartagena, 20-5-1884); $\mathrm{y}$ "[...] que el día anterior en la mina "Crianza» había resultado gravemente herido en la cabeza y pierna por desprendimiento de un canto, el trabajador José Ballesta López de 14 ańos de edad» (El Eco de Cartagena, 24-7-1890).

11 SCHEPER-HUGHES, 1984 y 1987. 
casos no redundaba en una mejora a medio o largo plazo de la condición socioeconómica del niño, por no decir que muchos acabarían muriendo, siendo vendido o explotados para el servicio doméstico, industrias, etc.), el abandono de niños en lo salvaje de un bosque, etc., que ha creado ejemplos literarios ${ }^{12} y$ hasta apellidos ${ }^{13}$. Es necesario que recordar que no es tan distinto abandonar a un niño a la suerte del bosque natural, o a la selva humana de las ciudades industriales. Y son solo ejemplos de la documentación histórica acerca de esta práctica, el infanticidio, que tanto antes como aún ahora para los siglos que aquí se tratan, existía.

En todos estos casos, si bien es cierto que no se provoca la muerte al instante (infanticidio directo), sí se realiza de forma pasiva, más lenta, pero igualmente efectiva. Harris (2010: 196, 2009: 138-139) considera ejemplos de infanticidio directo el estrangular al recién nacido, ahogarlo, asfixiarlo, golpearlo, etc. Como indirectos, métodos que van desde el dejar morir lentamente por hambre, a los que se encargan de descuidar la higiene, la integridad física y psíquica, exponerlos a los infantes a accidentes, no asistir al niño en la enfermedad, etc. Pienso que en el caso de los nińos mineros pudiera existir algo de este infanticidio pasivo, por negligencia o descuido, que anteriormente hemos tildado siguiendo a Harris de «infanticidio indirecto». Obligar al niño a pasar las duras jornadas de trabajo expuestos a derrumbes, explosiones, enfermedades reumáticas, respiratorias e infecciosas, no dista mucho de aquellos padres que abandonaban a sus niños a los elementos (atentando su integridad física), a los peligros de un bosque, como ha quedado inmortalizado por los Hermanos Grimm en el popular cuento de Hansel y Gretel, que relata un intento fallido de infanticidio.

Sin duda, nuestra mentalidad ilustrada, democrática y civilizada tilda de cruel el infanticidio, aun siendo pasivo, y está alerta hasta incluso al oír su nombre. Pero estos juicios, más morales que científicos, no han de nublarnos el juicio a la hora de poder analizar otras hipótesis para entender las razones que llevan a una familia a enviar, consciente o inconscientemente, a un nińo a la tumba. Porque el empleo de mano de obra infantil, como ilustra Guillén Riquelme en su trabajo (2009) no deja de ser un drama social, sea actual o pretérito, tenga el nombre que tenga. Y si es posible (de momento esto es solo una hipótesis falta de más documentación y reflexión) que este empleo de mano de obra infantil sea una forma más o menos indirecta o camuflada de infanticidio, llamémosle por su nombre.

Pero sea cual sea la razón, la realidad fue que los nińos acabaron siendo parte fundamental del engranaje que ponía en funcionamiento la industria minera de este

12 Ejemplo: Hansel y Gretel, recopilado por los Hermanos Grimm.

13 El más conocido es «Expósito», pero hay que relacionar que muchos apellidos con el nombre de un santo pueda deberse a que, al ser los niños abandonados en la puerta de una iglesia, convento, monasterio, etc., el apellido del mismo fuera el del titular del edificio santo, pasando estos niños a considerarse una especie de «hijos adoptivos» de dichos titulares. 
enclave murciano, de igual forma que los niños fueron usados como mano de obra en otros entornos industriales, en el campo y en el ámbito doméstico, siendo igualmente parte del mecanismo económico y laboral de los entornos en los que fueron explotados. Ser niño, con anterioridad a las declaraciones universales en pos de los derechos humanos y los de los niños en particular, nunca ha sido fácil, quizás menos que para los adultos. En algunos momentos, como en el Medievo, los nińos fueron vistos como adultos incompletos, pero aptos para el trabajo. Pero la niñez es una etapa fundamental en la vida y formación del ser humano, y ver de qué manera es entendida y respetada, nos aporta valiosa información sociocultural. Por lo que, sean cuales quiera que sean las razones que lleven al mantenimiento del trabajo infantil, ahora y antes, revela valiosa información de cómo entendemos la niñez y cómo se ha entendido; lo que ha su vez redunda en información acerca de nuestra sociedad entera, de nuestra concepción de nosotros mismos, de nuestra visión antropológica.

Profundizando aún más en el caso del niño minero, podemos dar algunos datos que nos ayuden a contextualizar la infancia en un entorno minero. Para expertos en la minería murciana, como J. B. Vilar, P. Ma. Egea Bruno y D. Victoria (1987: 125), la media del empleo de nińos en la cuenca minera era de aproximadamente un 30 por ciento, el doble que en el resto de Espańa. También es cierto que la realidad pudiera ser distinta, aunque quizás menos demostrable documentalmente, y el empleo en porcentaje de niños o menores de edad en las distintas labores de la minería, exterior e interior, sea superior a esa cifra. López Morell y Perceval Verde (2010: 121-122) recogen, por ejemplo, los porcentajes de nińos empleados, menores de 18 ańos, en las labores mineras del plomo y el hierro, dos de las explotaciones más importantes en la zona, desde 1868 a 1934 (ver gráfico 1).

Guillén Riquelme informa (2009: 179) que medios de comunicación como el Heraldo de Mazarrón, El Bragao o El Liberal, y entidades progresistas, de izquierdas y republicanas, "denunciaron el desolador espectáculo de niños raquíticos, enclenques y con todos los síntomas de una alimentación deficiente, entregados a duras faenas a las que se les obligaba en minas, lavaderos, terreras y calcinadoras, con un salario de entre 30 y 50 céntimos diarios, que ya en el año 1900 resultaba insuficiente sólo para reponer las energías consumidas en el trabajo». En las páginas siguientes, el citado autor recoge algunas anotaciones acerca del trabajo infantil en el mundo, pero en el que no vamos a profundizar.

Por lo que unido a lo anteriormente dicho con respecto a la hipótesis del infanticidio camuflado de trabajo minero, no sólo estos niños estaban desnutridos (¿̨no se los alimentaba correctamente porque no había alimentos para toda la familia o esta falta de nutrientes era intencionada, provocando la debilidad del menor, que enferme, accidente o muera más rápido?), sino que lo ganado no servía siquiera para su propia alimentación, 


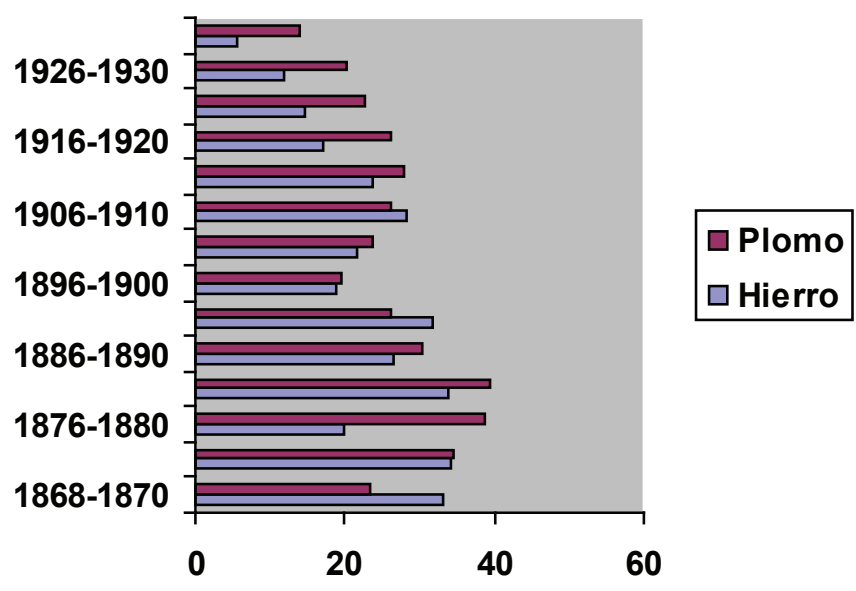

Gráfico 1: Empleo de niños menores de 18 años en la minería murciana de hierro y plomo entre 1868 y 1934. Fuente de los datos: Estadísticas Mineras, recogidas de López Morell y Perceval Verde (2010: 121-122).

por lo que de poco o nada podían colaborar en sus familias con sus míseros ingresos, por lo que de poco se sostiene la teoría de que el empleo de niños en las labores mineras sirviera para ayudar en los ingresos económicos de sus familias. Las razones no son sólo estas. López Morell y Perceval Verde (2010: 123), como otros investigadores, apuestan por la vía de que el trabajo infantil servia de complemento económico a sus familias, pero advirtiendo también una novedad en el discurso al respecto, y que en parte se mantiene en la dilatada producción historiográfica minera de Vilar y Egea Bruno: que el mantenimiento de esta forma de trabajo estaba relacionado con las ventajas económicas de no renovar e invertir en técnicas e infraestructuras mineras muy anticuadas. Además, que estas labores ilegales servían de escuela para los mineros futuros. Por lo que la dejadez para cambiar o hacer cumplir la legislación laboral que iba regulando poco a poco el trabajo infantil fracasaba porque era más rentable, en el sistema económico y laboral que regían las actividades mineras de los siglos XIX y XX, mantener el trabajo como estaba, es decir, sueldos bajos, insalubridad y falta de seguridad, inversiones mínimas, etc.

Quizás convenga extrapolar aquí algunas de las conclusiones del citado texto de Maureira, que lo concluye diciendo que «Para entender al fenómeno del trabajo infantil este debe ser puesto en el contexto de una estrategia de sobrevivencia que caracteriza a las familias pobres del país y que estas estrategias no corresponden a respuestas de adecuación de estas familias frente a situaciones coyunturales sino que son respuestas culturales frente a una situación de pobreza estructural» (2002: 122). Es decir, para entender la mano de obra infantil en la cuenca minera de Cartagena-La Unión hay que poner de relieve no sólo la situación económica (escasez generalizada) sino el contexto social y 
cultural en general que permitía dicha pobreza, una cultura económica caracterizada por poca inversión y poca modernización de las labores mineras, una legislación que no se respecta, etc. Por lo que las razones coyunturales de pobreza sólo explican parte del fenómeno, parte de las causas, pero no tanto el cómo solucionar el problema ni las respuestas culturalmente ideadas para ello.

Quizás lo anterior (infanticidio, mantenimiento de un sistema de trabajo determinado y cierta contribución a la economía familiar) sirva para responder a la pregunta de cómo era posible el empleo de estos niños en las labores mineras si, por ejemplo, la ley laboral de 24 de julio de 1873 (ley Benot) prohibía el empleo de nińos y niñas menores de 10 ańos en las labores de los entornos mineros, tales como las minas y fundiciones, así como talleres y fábricas. En el año 97 de ese mismo siglo se creó una especie de policía minera encargada de velar por la integridad de la legislación minera, pero como la ley laboral del 73, tuvo poca aplicación práctica. Como poco efectiva fue también la ley de 13 de marzo de 1900, que retomaba las directrices anteriores prohibiendo el trabajo infantil a menores de 10 años, limitación que en las labores subterráneas aumentaba hasta los 16 ańos, quedando a los menores de 14 años prohibido el trabajo nocturno. En lugares como La Unión son conocidos los casos en los que se falsificaba la partida de nacimiento para permitir a estos menores, muchos de 8 o 10 años, trabajar en las labores mineras quebrantando la ley. También hay noticias (López Morell y Perceval Verde, 2010: 122) de que Ayuntamientos como el de La Unión solicitaran modificar la ley para permitir que a los 14 ańos se estuviera apto para trabajar legalmente. Para presionar, estos y otros aducían que sin estos nińos, la producción minera se vería mermada por la falta de trabajadores. Y en parte tenían razón: como se ha dicho, prohibir estos trabajos infantiles obligaba a los empresarios a contratar más caro, y lo que es más importante, a realizar importantes inversiones en las minas. Una de las razones por las que eran preciados estos delgaduchos y malnutridos niños es que eran del tamaño perfecto para introducirse por los estrechos túneles cargando mineral en cunas (una especie de vagonetas) y otros contenedores de mano. Las labores de entibado y protección de túneles más espaciosos eran muy costosas, y menos rentables si existían niños a quienes explotar. Sin respuesta oficial, en 1908, por Real Decreto del Ministerio de la Gobernación de 25 de enero, se detalla que se prohíbe el trabajo a menores de 16 ańos en las labores de cortes y extracción de minas, canteras y hornagueros, así como el transporte de mineral. En otra ley de 1910, se prohíben las labores de interior a menores de 18 años para el arranque o uso de explosivos. El que continuamente se tenga que proclamar la ilegalidad de esta acción demuestra lo poco prácticas que habían resultado las leyes anteriores. Otra ley es la de 25 de mayo de ese año que obligaba a que los nińos menores de 18 ańos fueran a la escuela, escuelas que debían crearse también junto a talleres, minas, etc. Junto al interés de la explotación infantil en al conciencia social, estaba también el de las mujeres, a las cuales se las veía como poco aptas para trabajos mineros como los del interior de la mina, 
no ya por la peligrosidad de dichas labores, sino por tener que apreciar a hombres rudos, brutos y casi desnudos, aspectos estos que podían dañar la integridad moral de dichas mujeres. De todas formas, eran una mano de obra abundante en labores de exterior como los lavaderos. Cabe tomar por buena la reflexión de Guillén Riquelme (2009: 177) cuando afirma que ante una situación laboral tan deprimente los niños serían los más perjudicados, los más desfavorecidos dentro del colectivo laboral.

\section{REFERENCIAS AL TRABAJO INFANTIL EN LOS CANTES MINEROS}

Las alusiones a la infancia en el patrimonio inmaterial encarnado en la música minera es más que abundante. La mayoría de las letras aquí recogidas proceden del compendio de López Martínez de 2006, y podemos especificar, entrando ya en materia, que se encuentra el niño en dos tipos: el niño explícitamente trabajando (el «niño minero»), y el niño como «ente» general relacionado con una sociedad minera (no está explícitamente trabajando). Es el primero de estos el que aquí más nos interesa, precisamente, como es lógico, el que más se aluden en estos cantos que hablan tanto del trabajo en la mina. Pero no debemos olvidar la otra tipología, porque en algunos casos alude a nińos que no están trabajando en el tema que trata la coplilla pero que quizás sea minero, así porque, siendo hijo, hermano, etc., de minero y de una sociedad minera, ilustra sobre otros aspectos de la infancia en un entorno minero.

Seleccionaremos para ello algunas coplillas mineras que nos sirvan de ejemplo.

$-1-$

«Le dice un niño a su padre

por Dios no baje a la mina

si tengo que pasar hambre

yo imploro por las esquinas

aunque mi sufrir sea grande».

$-2-$

«Para ganar de comer

está el minero penando,

para ganar de comer,

mientras esté trabajando,

sus hijos y su mujer...».

$-3-$

«La crisis. Paro.

Honda miseria,

hijos sin pan,

mujer enferma.

Paño tendido sobre la acera.

Humillación,

rabia y vergüenza. 
De tarde en tarde

Cae una moneda.

Éxodo triste

hacia otras tierras...».

$-4-$

«Pobre peón de tercera

qué poca herencia dejó,

para el aire una minera

y al hijo que abandonó

ni su puesto en la cantera».

$-5-$

«De la entrada de la mina

sale el rico mineral

para que tengan berlina

los hijos de don Pascual».

$-6-$

«To(do)s van como un estampi(d)o,

a la boca de la mina,

y un niño quiere bajar,

que su pa(d)re no ha sali(d)o,

$\mathrm{y}$ abajo tiene que estar».

Los ejemplos aquí recogidos pueden quedar «clasificadas» como coplillas mineras en las que aparecen los nińos, pero no expresamente como trabajadores. Son, en concreto, hijos de mineros o empresarios. Con respecto a los niños de mineros representados en estos ejemplos, destacamos el uso de los nińos para retratar la situación de pobreza típica de las familias mineras. Se recalca que el sueldo del minero es insuficiente para alimentar a la familia, y que esta situación se agrava a la muerte del cabeza de familia, dejando a los huérfanos y a la viuda en una situación difícil, que quizás obligue a la mujer y a los hijos a trabajar (sino lo hacían ya), en el trabajo doméstico, en el campo, el las labores de la minería, en la prostitución. No existían, como ahora, medios que posibilitaran de forma real el mantenimiento de una familia donde moría la fuente principal de ingresos. Antes de continuar, dos aspectos que se necesita matizar. Es cierto que el sueldo del minero, sobre todo los no cualificados, los niños y las mujeres, eran muy bajos con respecto a la producción extraída. También es cierto que muchos de estos sueldos se pagaban con vales que sólo se podían canjear en establecimientos muy concretos, a menudo propiedad o designados por los propios empresarios mineros, y donde es común encontrar noticias del gran descontento ante estos vales, que a menudo implicaban precios más altos, menor calidad... Contra estos vales los mineros se rebelarán, siendo una de las piedras angulares del movimiento obrero en la comarca minera de Cartagena-La Unión, como por ejemplo en $1898^{14}$. Tanto

14 Ejemplos: «Con treinta y cuatro quintales que has saca(d)o desgarbillo/ te pones a darme un vale para la tienda El Vivillo/ que es más ladrón que Pernales»; "Ya se acabaron los vales./ Ahora yo cobro en dinero,/ en peseticas cabales./ Yo compro donde yo quiero,/ y pago en duros, o en reales»; 
del pago en vales como de la inferioridad del salario minero con respecto a las ganancias de los empresarios se hacen eco estos cantes mineros. Uno incluso de los que se han colocado en los ejemplos (5) alude a que de las penalidades del trabajo minero, salen las riquezas con las que unos, los pocos, pueden vestir bien, como los hijos de Don Pascual, y otros, se supone, visten peor, como los hijos de los mineros. No es tampoco desconocido otra de las causas de la pobreza minera, reflejado ello también en otras coplillas, en las que aparece el minero gastándose el sueldo en juego, alcohol y prostitución ${ }^{15}$. E incluso, hay alusiones a posibles menores borrachos ${ }^{16}$, otro drama que se debía juntar en estos ambientes al del trabajo infantil: niños haciendo de adultos, trabajando en las minas, y bebiendo, jugando y requiriendo de la prostitución como los adultos.

Pues bien, en ese ambiente en el que hay que suponer que la economía de una familia minera no era muy boyante, el que el marido (minero) se accidentara, muriera, fuera despedido o simplemente no pudiera trabajar más, sin tenerse accesos a sanidad, prestaciones por desempleo, jubilación, pagas por viudedad u orfandad, es normal que los niños fueran el colectivo más perjudicado. Estas letras señaladas recogen las tensiones cotidianas en las que la infancia está presente, bien porque se pasa hambre, bien porque su situación es diametralmente opuesta a la de los niños hijos de empresarios, o por el drama vivido por el nińo ante la condición minera del padre. En concreto me refiero a las letras 1 y 6 . En la primera, es la voz de un niño pidiendo al padre que cese en su labor de minero; que él se ofrece para mendigar. Ello nos ilustra muchas cosas: que el dinero conseguido por el minero no bastaría por sí solo para alimentar a la familia, al menos no para que pudiera servir dicho sueldo para compensar los enormes riesgos de la mina. Otra cosa que se extrae es que la mendicidad, sobre todo la infantil, debiera ser cotidiana y hasta normal. Y quizás la más importante, que la pérdida del

"Con los vales que me dan/ cuando en la mina me entierro/ en mi casa falta el pan/ yo valgo menos que el perro/ del malnaci(d)o de don Juan»; «iBendiga el cielo al ministro/ que obligó a pagar con reales/ el trabajo del minero!/ ¡Ya han quita(d)o los vales!»; o "Mal dolor les dé a los vales/ y al borde que los crió,/ que por no pagar con reales,/ aún estoy soltero yo».

15 Ejemplos: "Cuando está a morir el día/ al rematar el trajín/ siempre paro en Venta Fría/ avían la caballería/ ¡y después me avían a mí»; "Al despuntar la mañana/ voy a la, al trabajo/ y al terminar la jornada/ gasto el jornal a destajo/ donde a mí me de la gana»; «Baja el minero cantando/ cuando sale de la mina/ al pie de aquella colina/ mi novia me está esperando/ en el pico de la esquina»; "Cuando salga de la mina/ solo pienso en divertirme/ que no quiero que se diga/ cuando me llegue a morirme( que desperdicié mi vida»; "Yo me gasto en disfrutar/ cuando el trabajo termina/ lo que gano de jornal/ que algún día de la mina/ puede que no salga más»; «Echa otro vaso de vino/ no te lleves la botella/ porque bebiendo sin tino/ me parece menos negra/ la mina de mi destino"; " Echa una copa de vino/ y otra más y después otra/ que quiero en mi desatino/ enterrar en cada copa/ la angustia de mi destino»; "No me des a beber más/ que el vino me está matando/ porque me empiezo a alegrar/ y hasta me estoy olvidando/ que tengo que trabajar"; o "Anda y dile a la Gabriela,/ si vas a Las Herrerías/ que duerma y no pase pena/ que antes de que amanezca el día/ estaré yo en Cartagena».

16 Ejemplo: «Dónde andará ese muchacho./ Son las tres de la mañana,/ donde andará ese muchacho,/ si está bebiendo vino,/ si andará por ahí borracho». 
padre, y de sus posibles ingresos, sería una situación tal (económicamente hablando), que es mejor tener al padre vivo y ganando quizás menos en otras labores (por ejemplo el campo) que arriesgarse en un trabajo que podía dejarlo inválido o muerto, en cuyo caso no podría trabajar, ni como minero ni como nada, siendo una carga para la familia. La otra coplilla, la 6 , presenta al nińo en otra situación, no previniendo al padre de las consecuencias de la minería, sino experimentando él mismo el desánimo que sobreviene cuando una mina se está trabajando y una explosión llena de incertidumbre a las familias de los mineros por si su padre o esposo está vivo o muerto. Este niño, escuchando la explosión y no ver a su padre en la bocamina acompańando a sus compañeros de labor, este hijo minero (que no se sabe si trabaja en la mina o no) quiere bajar al interior y buscar allí a su padre.

Como resumen, podemos decir que las letras en las que se refleja la infancia, pero no explícitamente el empleo de menores en las labores mineras, están relacionadas con: el ambiente de crisis, pobreza y hambre de las familias mineras; el contraste entre la pobreza de los niños mineros y la opulencia de los niños hijos de empresarios; el niño alentando al padre a que busque otro empleo; y la preocupación del menor por su padre ante un accidente mineros.

Otro tipo de reflejo de la infancia, como en los ejemplos que se muestran a continuación, es el de los niños y su empleo en las labores mineras.

$-7-$

«Cada vez que nace el día caminito de La Unión sale andandito mi niño y atraviesa el alma mía con el dardo de su adiós».

-8 -

«Era un niño todavía ganando su primer jornal pero nadie lo creía por lo serio y lo formal que en la mina iba y venía». -9-

«Yo tenía un hermanico chico, que un barreno mató, $y$ me encuentro tan solico que a la mina voy yo para estar con mi hermanico». -10 -

«Es minero mi hermanico dice que a la mina baja y que va a golpe de pico 
todo el que en ella trabaja

ahondando en agujerito».

-11 -

«Nenico, sube al enganche,

y dile al enganchador,

que le diga a los torneros

que si queda mucho sol,

$\mathrm{p}(\mathrm{ar})$ a pegar otro barreno».

Es común, como se observa en las letras 9 y 10, la alusión al niño minero bajo el término de «hermanico». Se usa tanto en las letras que relatan los accidentes mineros con muerte de un menor o simplemente en aquellas (10) en la que se relata la visión el trabajo minero por un niño, narrando cómo se excava, pudiéndose interpretar «ahondando en agujerico» cierta alusión semántica a tantas otras letras mineras que tienen como motivo la muerte, y el minero en las entrańas de la tierra cavando su propia tumba. Pero no sólo estas letras que aluden al trabajo infantil en las minas van precedidas por «el hermanico»; otras, como la 11, aluden a «nenico», un nenico este en concreto inmerso en las labores de la minería, requerido por su agilidad y velocidad para servir de mensajero entre los torneros y otros encargados de transportar personas y materiales desde el interior al exterior (como los citados torneros y los enganchadores).

En otras letras, la 7 y la 8, no se retrata tanto al niño minero trabajando, pero sí o de camino a él o aludiéndolo indirectamente. En la 7 se aprecia la voz de una madre o un padre sintiendo la despedida del nińo al alba, antes de empezar su rutina minera, como en estado de alerta y dolor permanente. Ciertamente estas madres y esposas de mineros debían comportarse quizás de forma parecida a las madres y esposas de los toreros, que sentían con dolor la pérdida del torero camino a su faena y que la inquietud no era abandonada hasta el que torero volvía a casa. Otro tipo de letras mineras expresan la alegría, sobre todo de la madre o esposa, al ver volver vivo y sano a su minero. Quizás estas mujeres de mineros, como las de los toreros, dedicaban las horas de labor a rezar, pidiendo en los cielos seguridad y suerte bajo tierra. Es mucha la presencia de elementos religiosos en las letras mineras en general, siendo la Virgen del Rosario (patrona de la localidad), Santa Bárbara (patrona de mineros), y el Cristo de los Mineros las figuras sagradas más aludidas.

La letra restante es más difícil de interpretar, pero es a la vez, quizás, la más sencilla. Ilustra el asombro, quizás popular, de que alguien tan formal y serio (¿en contraposición al resto de personas dedicadas a la minería?), y que pese a esa inocencia infantil, esa pureza, se ganaba el dinero trabajando en las minas.

Como podemos ver, la infancia en un entorno minero como el de Cartagena-La Unión trasciende los ámbitos de las listas con los porcentajes de los niños empleados en 
la minería, su sueldo, las noticias de sus accidentes en la prensa de la época, la legislación que iba prohibiendo su empleo pero que las instituciones luchaban por preservar, etc. La infancia transciende lo material para trasladarse a lo inmaterial. Ha quedado perfectamente inmortalizado el nińo y el entorno minero en el que vivió su infancia en el folklore musical de los cantes mineros. Los ejemplos aquí relatados son un número pequeño, una muestra de una colección aún mayor de ejemplos donde los niños, mineros o simplemente niños, están directa o indirectamente retratados. Esperamos profundizar aún más en estos estudios de la infancia en el patrimonio inmaterial en sucesivos trabajos.

\section{BIBLIOGRAFÍA CITADA}

GUILLÉN RIQUELME, M. C., 2009: «El drama social del trabajo infantil en los distritos mineros de La Unión y Mazarrón», Argentvm, 1, pp. 175-186.

HARRIS, M., 2009: Antropología cultural, Alianza, Madrid.

HARRIS, M., 2010: Nuestra especie, Alianza, Madrid.

JACCARD, P., 1977: Historia social del trabajo: de la Antigüedad hasta nuestros días, Plaza \& Janés, Barcelona.

LÓPEZ MARTÍNEZ, P., 2006: Compendio y análisis de la letra minera (en la comarca de Cartagena-La Unión), Universidad de Murcia, Murcia.

LÓPEZ MORELL, M. Á, y PÉREZ DE PERCEVAL, M. Á., 2010: La Unión. Historia y vida de una ciudad minera, Almuzara, Córdoba.

MARTÍNEZ SOTO, Á. P., NAVARRO ORTIZ, D., y PÉREZ DE PERCEVAL, M. Á., 2004: La vida en la Sierra Minera de Cartagena. Evolución demográfica de la diputación de El Beal, 1880-1970, Ediciones Laborum, Murcia.

MAUREIRA ESTRADA, F., 2002: «Trabajo infantil. Algunas consideraciones antropológicas», Revista Austral de Ciencias Sociales, 6, pp. 113-124.

MOUZO PAGÁN, R., 2003: «Explotación infantil en la minería cartagenera», Conferencia en el I Congreso Etnográfico del Campo de Cartagena (s. p.)

PÉREZ DE PERCEVAL VERDE, M. Á., y SÁNCHEZ PICÓN, A., 2005: «El trabajo infantil en la minería española, 1850-1940», comunicación en VIII Congreso de la Asociación Española de Historia Económica, Santiago de Compostela-Vigo, Septiembre. 
RÓDENAS ROZAS, F. J., 2004: «La caza del aliento imposible: el retrato mortuorio en La Unión», Revista murciana de antropología, 11, pp. 225-238.

ROJAS, J., 1999: «Trabajo infantil en la minería: Apuntes Históricos», Revista de Historia. Instituto de Historia. Pontificia Universidad Católica de Chile, 32.

SAURA VIVANCOS, S., 2004: La Unión, ayer y hoy, Ayuntamiento de La Unión, Murcia.

SCHEPER-HUGHES, N., 1984: «Infant mortality and infant care: cultural and economic constraints on nurturing in northwest Brazil», Social Science and Medicine, 19 (5), pp. 535-545.

SCHEPER-HUGHES, N., 1987: "Culture, scarcity and maternal thinking: mother love and child death in northeast Brazil», en SCHEPER-HUGHES, N., Child survival, Springer, Boston, pp. 187-208.

SCHILDKROUT, E., 1980: «Nuevas reflexiones acerca del trabajo de los niños», Revista Internacional de Ciencias Sociales, 32 (3), (s. p.).

VILAR, J. B., EGEA BRUNO, P. Ma., y FERNÁNDEZ GUTIÉRREZ, J. C., 1991: La minería murciana contemporánea (1930-1985), Instituto Geológico y Minero de Espańa, Madrid.

VILAR, J. B., EGEA BRUNO, P. Ma., y VICTORIA, D., 1987: El movimiento obrero en el distrito de Cartagena-La Unión (1840-1930), Academia Alfonso $\mathrm{X}$ el Sabio, Murcia.

VILAR, J. B., EGEA BRUNO, P. Ma., y VICTORIA, D., 1990: La minería murciana contemporánea (1840-1930), Universidad de Murcia, Murcia. 